\title{
Thinking as a Student: Stimulating Peer Education with an Undergraduate Teaching Assistant in the Humanities Classroom
}

\section{Lara Karpenko ${ }^{1}$ and Steven Schauz ${ }^{2}$}

\begin{abstract}
In this article, I argue that peer educational experiences should be incorporated into the undergraduate humanities classroom by providing a case study of a successful Undergraduate Teaching Assistant (UTA) pilot. In keeping with Topping \& Ehly's (2001) criteria for successful peer education, I assigned the UTA a significant role in direct instruction. Partly owing to the UTA's active classroom role, the experience enhanced learning for students and helped me create a dynamic, critically-engaged class environment. The experience also provided an opportunity for the UTA to engage in deep learning and develop a professional identity; near the end of this article, the UTA shares his reflection about the experience.
\end{abstract}

Keywords: Peer education; Undergraduate Teaching Assistant; Humanities

Education; Case study

Undergraduate peer instruction has long been regarded as an effective tool for enhancing student engagement and for developing valuable transferable skills (Basinger, Peterson, \& Spillman, 1984; Bichy \& O’Brien, 2014; Fingerson \& Culley, 2001; Gordon \& Dempster, 2013; LaPlant, Mason \& Singh, 2010; Micari, Streitwieser, \& Light, Trimble, Carter, 2005). ${ }^{3}$ Writing as early as 1975 , Scott McNall deemed peer educators a "hidden resource," as he called on faculty from his field of sociology to leverage undergraduate knowledge to promote deep learning (136). Since that time, McNall's challenge has been met by faculty and staff from beyond the field of sociology in order to invigorate undergraduate educational experiences across a variety of institutional settings and learning contexts.

Peer educators have experienced particularly high degrees of success in Undergraduate Teaching Assistant (UTA) programs (Adler, 1993; Bernstein, 1984; Cook, 2002; Fernald, Chiseri, Lawson, Scroggs \& Riddel, 1975; Fremouw, Millard, \& Donahoe, 1979; McCormick \& Shofner 2010; Mendenhall \& Burr, 1983; Murray, 2015; Socha, 1998). ${ }^{4}$ As peer educators with significant teaching roles in classroom settings, UTAs can have a wide range of duties depending on programmatic or institutional needs (Socha). For instance, Cook \& Bernstein assigned grading duties to UTAs while Adler, McCormick \& Shofner, and Streitwieser \& Light all emphasized that UTAs can be effective discussion leaders, Mendenhall \& Burr and Bichy \& O’Brien expected their UTAs to hold office hours and Murray provided UTAs with service learning opportunities. As wide-ranging as the UTAs' duties might be, all the scholarship points to one consistency:

\footnotetext{
${ }^{1}$ Department of English and Modern Languages, Carroll University, 100 N. East Ave., Waukesha WI, 53186, lkarpenk@carrollu.edu.

${ }^{2}$ College Student Personnel, Western Illinois University, 1 University Cir., Macomb IL 61455, sr-schauz@wiu.edu.

${ }^{3}$ Please note that this list is far from exhaustive.

${ }^{4}$ This list is also not exhaustive.
} 
incorporating UTAs leads to almost uniformly positive results for UTAs, for faculty mentors, and for all students involved in the process. Despite the high success rate of UTAs and though the scholarship detailing this success is fairly extensive, there has been very little sustained discussion surrounding UTAs in humanities courses. While work by Smith (2008) and McCormick \& Shofner (2010) provide valuable exceptions to this tendency, with the exception of the field of Rhetoric and Composition, UTAs remain relatively foreign resources in humanities courses in general or in literature classrooms in particular.

To some extent, the relatively limited discussion surrounding UTAs in humanities courses reflects a larger and troubling trend. Though many, if not most, humanities instructors regularly incorporate informal peer-based pedagogies such as group work, classroom discussion, and student-led presentations into their courses, there is far less evidence to suggest that humanities instructors gravitate towards the more formalized methods of peer instruction that underpin UTA experiences. But by embracing students as partners in our classrooms, we create dynamic spaces that encourage content-level engagement and professional development. Fortunately, as work by Eby \& Gilbert (2000), McCormick \& Shofner (2010), and Tompkins, Smith, \& Eby (1990) all demonstrate, peer education in the humanities is fast becoming the welcome subject of a growing scholarly conversation. Still, when compared to the robust work surrounding UTAs in the sciences and social sciences, it seems clear that that this conversation must be widened.

Desiring to experiment with more formalized methods of peer education and inspired by the robust scholarship detailing the efficacy of UTAs, I recently incorporated a UTA into a semester-long general education course on Postcolonial Literature and Theory (PLT). In this article, I provide a case study of that pilot experience. ${ }^{5}$ In designing/assigning the UTAs duties, I was influenced by Topping \& Ehly's (2001) criteria for successful peer education-particularly by their suggestions that peer education should be beneficial to all parties, that it involve conscious teaching by the undergraduate, and that it be professionally supervised (2001). Especially inspired by their suggestion that peer educators should be involved in "conscious teaching" and in contrast to many UTA programs, I assigned the UTA, Steven Schauz, a significant role in direct instruction. Altogether, Schauz, a senior English major who had taken the course previously (from a different instructor) and received an "A," was responsible for about $20 \%$ of class instruction. Partly owing to Schauz's active classroom role, the UTA experience enhanced learning for students and helped me create a dynamic, critically-engaged classroom environment. The experience also provided an opportunity for Schauz to engage in deep learning and develop a professional identity; near the end of this article, Schauz, now a Masters student in a College Student Personnel program, shares his reflection about the experience. Overall the success of this pilot suggests that Undergraduate Teaching Assistant programs and peer educational experiences more largely can and should be incorporated into the undergraduate humanities classroom.

\section{The Experience}

I teach in the English department at a small comprehensive university and our general education program has a focus on cultural competency. Because of this cultural focus, our department's course on PLT draws a wide cross-section of students. Though PLT can count towards the English major, the prominence of this course in our general education program ensures that English majors represent only a small percentage of the class population in any given semester. During the

${ }^{5}$ Please note that the IRB board at my institution declared that this study was exempt.

Journal of the Scholarship of Teaching and Learning, Vol. 17, No. 3, July 2017. josotl.indiana.edu 
semester that I piloted the UTA experience (Fall 2014), out of the 27 students in the course, only one was an English major. None of the students knew that that the course would include a UTA prior to enrollment.

I selected Schauz for this experience because of his academic aptitude, his interest in graduate school, and because, as a Resident Assistant, he also had experience in peer supervisory roles. Further, Schauz and I had worked together the previous summer on an institutionally-funded grant which allowed him the opportunity to read deeply on postcolonial theory; he was thus able to start the semester with fairly extensive content-based knowledge. Schauz was not financially compensated for this experience; however he did receive elective credit which allowed him to fulfill one of the requirements towards his English major. While this course was part of Schauz's regular semester load. I taught the course as an overload and received a small amount of compensation.

As a UTA, Schauz was asked do to the following:

1) Teach a week long unit of the course (4 hours of classroom instruction).

2) Lead study review sessions before the midterm and final exams. (One class session per exam: 4 hours of classroom instruction).

3) Lead one class session on effective strategies for writing the argument-driven research paper (2 hours of classroom instruction).

4) Hold weekly office hours.

5) Attend every class session and keep up with all course readings.

6) Attend weekly meetings with me in order discuss a series of pedagogy-focused readings and discuss lesson plans.

As I mentioned earlier and as the above list suggests, I was influenced by Topping \& Ehly as I developed the UTA's role. I also elected to remove Schauz from any duties which involved grading - a departure from many UTA programs. This was partly done in order to preserve the privacy of undergraduates at a very small institution, but more importantly, I made this decision in order to ensure that the UTA's relationship to the students was defined by a mutually-beneficial sense of inquiry instead of results-based assessment. Further, as I detail above, Schauz was responsible for teaching 10 out of the 52 hours the course met in total. Though it was perhaps a bit unconventional to assign almost $20 \%$ of the course's total instructional time to an undergraduate, it was possibly the most successful part of the experience: it helped him take ownership over his own leadership role (i.e., it positioned him as a "conscious" educator of his peers), and resulted in deep learning for the UTA and the students (beneficial for all parties.)

In order to help Schauz succeed in his teaching experience, I ensured he received pedagogical training and support (professional supervision). In particular, I instituted the following six procedures/protocols:

1) Strategic syllabus planning

I planned the syllabus so that Schauz's first teaching experience did not occur until mid-semester: after he had observed me teaching the course for about six weeks, after he and I had discussed the course itself (in terms of the syllabus, goals, theoretical framework), and after he had completed some of the major pedagogical readings.

2) Direct-pedagogical instruction

Journal of the Scholarship of Teaching and Learning, Vol. 17, No. 3, July 2017.

josotl.indiana.edu 
Karpenko and Schauz

Schauz came to the UTA experience with a fair amount of content knowledge but comparatively little pedagogical training. In order to provide this training, we, as I suggest above, met weekly in order to discuss significant pedagogical readings (e.g., John Dewy's “The Need for a Philosophy of Education” and Sheridan Blau's The Literature Workshop). After we had read and discussed the pedagogical readings, I asked Schauz to submit a teaching philosophy statement in which he articulated how his personal philosophy of education aligned with (or departed from) the goals of the pedagogical theorists we covered.

3) UTA lesson planning and review

Before each class session that he led, I required that the UTA submit a lesson plan that explained how his plan connected to his own teaching philosophy. We discussed his philosophy statement, his lesson plans, and his pedagogical goals during our weekly meetings.

4) Empowering the UTA

In order to help students in the course view Schauz as a course leader (even though he was not responsible for any grading), I ensured that he was ultimately responsible for all his pedagogical decisions. For instance, during the content-based unit he taught, Schauz was responsible for selecting all course texts (including the specific editions), writing his lecture and leading all class discussions. For the skills-based courses he led (i.e., midterm/final review and writing workshops), he was responsible for designing all sessions and thinking through the issues of scaffolding and review. In all the sessions he taught I participated only as an active student.

5) Feedback and debriefing

After each session that he taught, Schauz and I would meet and discuss his lesson: what I observed, what he observed, and the overall strengths and shortcomings of the lesson. During these discussions, we were also guided by his philosophy of education and discussed how the course sessions met (or failed to meet) his pedagogical goals.

As I have articulated, this experience was at once elastic and highly regulated—allowing the UTA a considerable amount of authority within a carefully scaffolded framework. This structure proved successful, suggesting that this experience can and should be replicated in future humanities-based courses.

\section{Evaluating the Experience}

I will discuss the benefits of the UTA experience according to two of the three parties involved in the course: the students and me as the instructor. Schauz will then discuss the benefits and the challenges of the UTA experience from his perspective. ${ }^{6}$

\section{Benefits for the Students and Instructor}

As I mentioned earlier, students had enrolled in the course without knowing there would be a UTA. On the first day of class, I explained Schauz's role-emphasizing that he would not be grading but

\footnotetext{
${ }^{6}$ For those interested in further discussion, Schauz and I spoke about the UTA experience on Scrawl Radio out of De Paul University in Chicago, IL. Please go here to listen to the show.
}

Journal of the Scholarship of Teaching and Learning, Vol. 17, No. 3, July 2017. josotl.indiana.edu 
that he would be teaching certain days of the course and holding office hours. At the end of the semester, in order assess student engagement with the UTA experience, I conducted a survey (19 out of 27 students responded). (Please see appendix for entire survey.) I also took more informal notes and made observations throughout the semester.

During the first half of the semester, when Schauz's role was mostly limited to observation, students did not respond to the UTA much at all and his office hours remained largely unattended. After Schauz taught his first class session (an extensive midterm review), students began to turn to him more; and after he taught his week-long content-based unit and then led a writing workshop, students embraced Schauz's role as a UTA and readily turned to him as a resource. By the end of the semester, his drop-in office hours were extremely busy. Along these lines, nearly $30 \%$ of the survey respondents answered that they had met with Schauz at least once during the semester and the vast majority of those students met with him between 2-4 times during the semester. (This was in addition to the required meetings every student had with me.) Further, of the students who answered that they had met with Schauz, 100\% indicated that they found their meetings with him to be "extremely helpful" (the other potential categories were "helpful," "neither helpful nor unhelpful," "unhelpful,” and "extremely unhelpful”). In other words, the data suggests that students appreciated having an UTA to consult with outside of class. As one student commented "I found [Schauz] to be an invaluable resource. He thought as a student and provided wonderful intellectual insight when I was at a roadblock for my paper." "He was very knowledgeable on the class material" commented another student. "[He] made sure I left with all of my questions answered.” (Anonymous, Survey, December 2014).

Student respondents also positively evaluated Schauz's teaching with over 70\% describing it as "superb" or 'good." The narrative comments were once again positive and enthusiastic. "It was helpful and reassuring to hear tips from a student, since he can relate to us with the pressure of exams and papers" commented one student; another student suggested that "it was nice to get the information from a student" and another student wrote "Honestly, I could envision him being a professor himself; everything he said clicked with me and I learned a lot from his sessions." Though some students did report mild dissatisfaction (approximately 6\% of respondents described Schauz's teaching as "average”), the majority of respondents suggested they were pleased with the UTA's teaching. ${ }^{7}$

Students also responded positively to the general experience of having an UTA. When asked to rate their overall impression of the experience, over $50 \%$ of students responded that they "loved having a UTA" while $42 \%$ of students responded that they "liked having an undergrad TA" and 5\% (i.e., one student) respond that s/he "mildly" disliked having an undergrad TA claiming that "TA's [are] not a selling point for admission." The positive narrative comments however overwhelmed the single negative one. "I think it was good to have him as a resource" one student answered, "sometimes it can be more convenient than having to reach out to a professor." Another student commented that Schauz "was an effective, additional resource and teacher in the class!" Other comments include "I thought that it was good to have another person in the room besides the professor to come to for help. It sometimes is not as intimidating when the TA is an undergrad just like the students;" "I loved being able to go meet with Steven in a casual environment outside of class to ask any questions I may have;" "It was nice having another person to approach with

\footnotetext{
${ }^{7}$ About $23 \%$ of respondents skipped the numerical ranking and only provided narrative comments; however, since the narrative comments were almost uniformly positive here, I surmise that the students were pleased with Schauz's teaching.
}

Journal of the Scholarship of Teaching and Learning, Vol. 17, No. 3, July 2017. josotl.indiana.edu 
questions and the extra office hours were great;" and "I think he contributed to the class with helpful tips and another view of the material. He provided a peer influence that was not intimidating... I liked the fact that he did not do any grading, but rather contributed to our learning that was led by the instructor."

Overall, though the sample size was admittedly somewhat small, the data and the narrative comments reveal that students embraced the prospect of a UTA and saw Schauz as a valuable resource. Further, though grades did not necessarily go up from previous years, I noticed that students seemed more willing to engage with some of the course's more difficult theoretical material as they wrote their papers. For instance, I have taught this course for about ten years and always include Gayatri Spivak's “Can the Subaltern Speak?” on the syllabus. Students understandably find this text very difficult and have generally avoid referring to it as they write their papers. Schauz, however, followed up my initial lecture and discussion of the text by referring to Spivak extensively during the unit he taught. For the first time that I can remember, students extensively and intelligently incorporated Spivak's theories in to their final papers. Though there are of course many reasons that can explain this (personality of the students; stronger lecture/discussion from me, etc.), I attribute the students' sudden comfort with Spivak to the incorporation of a UTA. Seeing an undergraduate speak about and grapple with Spivak's theories was powerful to the students and Schauz was able to encourage students to overcome their trepidation and think about Spivak's theories deeply and meaningfully. This is just one example of course. But overall, the student level of discourse in this course was markedly higher than in previous years and to me, this is inextricably linked with the presence of a UTA in the course. Further, the UTA experience inspired students to learn from one another in a way that struck me as particularly profound. Far from detracting from the goals of the humanities, peer education led to a quintessential humanities-learning experience-one in which students engaged deeply with the source material and grappled with complex problems. As the semester progressed, there were moments in which students almost seemed to forget my presence as they turned to Schauz and to one another as co-educators--inspiring an active classroom environment defined by discussion and exploration.

On a personal level, I found this experience was deeply rewarding. In fact, this experience has indelibly altered how I approach course design. Though I always emphasize active learning strategies as I teach, I now deliberately seek opportunities to weave peer- educational experiences into the organizational fabric of my courses. Though in some ways, this experience admittedly required time and energy, it also-perhaps counterintuitively-energized my teaching. Incorporating a UTA seemed to render my teaching and lectures more relevant to the students and helped general education students embrace the importance of a liberal arts education. Throughout this experience, I seemed to occupy a role that cannot be quite described by either the "sage on the stage" or the "guide on the side" paradigms. I was something of both and of neither-functioning instead as an integral member of this discourse community.

Benefits for the UTA: a reflection by Steven Schauz

When I first heard of the opportunity, I was excited by the possibility, especially as I recognized that I would be a bit of a test subject for this model. I was honored to be considered for this role, but I also struggled at first to see how I could fulfill its expectations. But I accepted the offer as my excitement far outweighed my doubts. Sometime after this experience now, I am pursuing graduate studies in a College Student Personnel program, and have finished my first year of a

Journal of the Scholarship of Teaching and Learning, Vol. 17, No. 3, July 2017. josotl.indiana.edu 
Master's program. I absolutely believe that my experience as a UTA made me an attractive candidate for admission and helped prepare me for graduate study.

The UTA experience included two major components of study and practice: pedagogical and postcolonial theory. The pedagogical preparation as well as the actual experience of teaching challenged me to think about the ways that I interacted with and continue to interact with students. As a UTA, I had the opportunity to witness several "a-ha" moments for a collection of students, most frequently when they were struggling with some concepts, with incorporating new information that challenged their hegemonic perspective, or with composing a paper. For the students who came to me as a resource, I was often present to guide them through the process. It was as if they were on a journey of learning, but that some obstacle had blocked their path. When they received some of my guidance, it was as if they were able to move past this obstacle, and that is when the lightbulb would ignite. Helping to provide this guidance to students was something that I thoroughly enjoyed, and also has become a very helpful experience as I have continued in my graduate studies and often use similar skills with a new group of students.

Throughout the UTA semester, I made efforts to perceive learning as a partnership: that the instructor can and should learn from their students just as much if not more than their students learn from them. When I entered the UTA experience, I had an understanding that, while my professors had greater degrees of knowledge in a subject, I also had to make meaning for myself. I understood that I should value the teachings of the professor, but I also had to question, explore, and make salient the curriculum on my own. I came into the UTA experience knowing that I would also be learning in the classroom setting that I was now responsible for instructing, as well as from the readings, lesson planning, and discussions with Dr. Karpenko. However, I did not realize just how much I would be learning about my teaching and my ideas from the students. Their ability to ask questions of me (which I was not always prepared for) or create an interpretation of a text (that I had never conceived) challenged me, at times made me a little uncomfortable, but ultimately demanded that I learn, that I go back to the texts to reread, that I look deeper or at different pedagogical perspectives and that I become fluid in my teaching practice.

Further, when I first began reading about educational pedagogy, I was a bit caught up in the lofty premises of the theories. I envisioned these techniques in a very theoretically perfect fashion. Yet, I very quickly learned that the classroom setting is not this perfect system. In fact, it was often radically different. Then the question became: how do I apply the framework of the theory to this particular reality? What will work? What won't? Theory is fascinating and an important tool, but it is an illusion to think a theory will translate seamlessly in-to practice. I quickly learned that theory could not answer all of the anomalies, behaviors, conversations, or questions that arose within a classroom, but rather that it ought to be used to inform and frame my practice. One of the greatest challenges for me was to overcome the assumed rigidity of a given theory and to perceive the fluidity of its perimeters in practice.

The UTA experience also increased my subject-area knowledge of postcolonial theory. I am someone who is fascinated by complex subjects. Perhaps it is because I grew up playing puzzles and brain-teasers as a child, but I still thoroughly enjoyed putting the pieces together. I felt as if I was at a point in my academics where I could help others put these pieces together. But without the UTA experience, I might not have reviewed and sought to understand the components of the theory in quite as much detail. In short, I think that I needed to spend more time with the theories in order to disseminate a sense of understanding to the students I was working with, and that demanded that I construct frameworks about postcolonial theory in my mind in relation to other perspectives. The meanings that I have constructed of postcolonial theory, and of how I

Journal of the Scholarship of Teaching and Learning, Vol. 17, No. 3, July 2017. josotl.indiana.edu 
approached my pedagogy on the subject, have persisted in my current studies and professional practice.

In short, the UTA experience provided me an opportunity to explore subjects that interested me, to challenge myself to learn more and to see in more than a singular perspective, and to be critical and intentional in my pedagogy. I continue to consider this one of the most impactful educational experience I had during college. I think it helped me to grow as a person and as a student, and it continues to shape the realities through which I interpret my current studies as well as inform how I interact with students in my professional practice. We talk a lot about preparedness - about how a student feels prepared to graduate from an institution and confident in their ability to use their skills in the real world. For me, this experience brought me to a point of preparedness. I have a feeling that the UTA experience has the potential to have similar effects on others who are able to rise to the challenge and who receive guidance from their mentoring faculty member. Overall, it was an exciting, challenging, and meaningful experience.

\section{The Future}

The benefits of this UTA experience-even on the small scale that I described-were profound; however, because I advocate a program model that removes UTAs from grading responsibilities and instead recommend pedagogical training and supervised instruction, the experience I describe cannot be considered a cost or time savings as promised by Cook (2002). Instead, in keeping with Eby \& Gilbert (2000), the experience demanded a considerable amount of my time and because Schauz received credit via an independent study for which I was compensated, the experience also required a small amount of financial support from my institution. In addition, establishing institutional or departmental programing takes time and though my department was impressed by the results of the study and is interested in making the opportunity a part of our regular offerings, we have not yet instituted a formal UTA program.

Despite the potential difficulties of instituting a department- or institution-wide UTA program, many aspects of what I describe above can be easily incorporated in to any humanities course. For instance, student groups can be assigned to teach certain units of a course and to display content knowledge as well as knowledge of pedagogical best practices during their teaching units; students can be assigned roles as content experts and asked to conduct "mini-courses" throughout the semester; students can elect a student leader to oversee aspects of exam review etc. Overall, the low cost/high benefit of the program certainly suggests that UTAs can and should be incorporated into humanities courses.

Perhaps more profoundly, this case study also suggests that humanities courses - even those courses that tackle complex theoretical material-can benefit from peer educational experiences. On that note, I want to close by suggesting that UTA programs and peer educational experiences can help us think through some of the profound challenges that face humanities departments today. While I do not want to paint an overly optimistic picture of what peer educational programs can accomplish, I do want to emphasize that such programs constitute the essence of humanities study. Indeed, I partly write this essay in order to encourage those of us in humanities-based fields to embrace rather than retreat from the rigorous dialogue and the topsy turvy sense of authority that lend vitality to our disciplines. In so doing, we can invigorate our own practice and perhaps even encourage entire campus communities to understand why the humanities remain necessary in our complex and rapidly changing world.

Journal of the Scholarship of Teaching and Learning, Vol. 17, No. 3, July 2017.

josotl.indiana.edu 


\section{Acknowledgements}

I would like to thank Lauri Dietz, Director of the University Center for Writing-Based Learning at De Paul University for the help she provided as I was thinking through the UTA experience, for her invaluable insight as I was thinking through this essay conceptually, and for arranging our interview on Scrawl Radio.

\section{Appendix I: Survey for Students regarding the UTA experience}

Please answer the following questions. Your answers will be really helpful as we think about the role of peer education in our department. You can skip any question and still complete the survey. Your answers will be kept anonymous.

1) How many times did you meet with the undergrad TA outside of class?
a) More than 5 times
b) Between 2- 4 times?
c) 1 time?
d) 0 times?

2) If your answer to \#1 was yes, why did you meet with the undergrad TA? (Check all that apply)

a) Help with midterm or final exams

b) Help with final paper

c) Other reason (Please specify)

3) If you visited the undergrad TA outside of class, please rank how helpful you found the meeting(s) on a scale of 1 to 5 . (5 being exceptionally helpful and 1 being not helpful at all.)
a) 5
b) 4
c) 3
d) 2
e) 1

4) Please explain why or why you did not find the undergrad TA helpful when you met. If you did not meet, please explain why.

5) Altogether the undergrad TA led five days of class (one day of midterm review; two days on the The Wild Irish Girl; one day of writing tips and tricks; and one day for the final exam review.) Of these five teaching days, how many did you attend?
a) 5 days
b) 4 days
c) 3 days
d) 2 days
e) 1 day

Journal of the Scholarship of Teaching and Learning, Vol. 17, No. 3, July 2017. 
6) If you attended at least 1 day of the undergrad TA's teaching, please explain your reaction to his teaching. Was he effective? Ineffective? If you did not attend any days of his teaching, please say why.

7) If you attended the undergrad TA's two classes on The Wild Irish Girl, please rate his teaching on a scale of 1 to 5 (5 being exceptionally taught and 1 being poorly taught.) Please briefly explain your impression.
a) 5
b) 4
c) 3
d) 2
e) 1

8) This is the first time that the English department has made use of an undergraduate TA and we would like to know your overall impression of your experience. Please rate your experience according to the following. Please briefly explain your impression.

a) 5

I loved having an undergrad TA and would encourage the English department to make use of undergrad TAs in the future.

b) 4

I liked having an undergrad TA. Perhaps the English department should make use of undergrad TA's in the future.

c) 3

I am neutral on having an undergrad TA. I am unsure/undecided if the English department should make use of undergrad TA's in the future.

d) 2

I mildly disliked having an undergrad TA. I think the English department should avoid having undergraduate TAs in the future.

e) 1

I completely disliked having an undergrad TA. I think the English department should never do this again.

9) Would you be interested in serving as an undergraduate TA in your major? Why?
a) Yes
b) Maybe/Unsure
c) No

\section{References}

Baisinger, W., Peterson, G., \& Spillman, B. (1984). Undergraduates as Colleagues: Using Undergraduates as Teaching Assistants in the Basic Course. Association for Communication Administration Bulletin, 47, 60-63.

Bernstein, D. (1979). Reliability and Fairness of Grading in a Mastery Program. Teaching of

Journal of the Scholarship of Teaching and Learning, Vol. 17, No. 3, July 2017.

josotl.indiana.edu 
Karpenko and Schauz

Psychology, 6(2), 104- 110.

Bichy, C. \& O’Brien E. (2014). Course Redesign: Developing Peer Mentors to Facilitate Student Learning. Learning Assistance Review, 19(2), 43-57.

Cook, J. (2002, November). Undergraduate Teaching Assistants: The Relationship between Credibility and Learning in the Basic Communication Course. Paper presented at the 88th Annual Meeting of the National Communication Association, New Orleans, LA.

Eby. K, \& Gilbert P. (2000). Implementing New Pedagogical Models: Using Undergraduate Teaching Assistants in a Violence and Gender Learning Community. Innovative Higher Education, 25 (2), 127-142.

Fernald, P. Chiseri, M. Lawson, D, Scroggs, G. \& Jeanne C. Riddell, J. (1975). Systematic Manipulation of Student Pacing, the Perfection Requirement, and Contact with a Teaching Assistant in an Introductory Psychology Course. Teaching of Psychology, 2(4), 147-151.

Fingerson, L., \& Culley, A. (2001). Collaborators in Teaching And Learning: Undergraduate Teaching Assistants in the Classroom. Teaching Sociology, 29(3), 299-315.

Fremouw, W., Millard, J \& Donahoe, J. (1979). Learning-Through-Teaching: Knowledge Changes in Undergraduate Teaching Assistants. Teaching of Psychology 6(1), 30-33.

Gordon, J., Henry, P., \& Dempster, M. (2013). Undergraduate Teaching Assistants: A LearnerCentered Model for Enhancing Student Engagement in the First-Year Experience. International Journal of Teaching and Learning in Higher Education, 25(1), 103-109.

Haskey, Brandon. (Host and interviewer). (2015, November 14). “The Academic Pot of Gold” Scrawl Radio, De Paul University Chicago, IL.

LaPlant, J. (2010). Peer Mentoring in Undergraduate Research. Council on Undergraduate Research Quarterly, 3(2), 5-6.

Mason, A. \& Chandralekha, S. (2010). Using Reflection with Peers to Help Students

Learn Effective Problem Solving Strategies. AIP Conference Proceedings, 1289(1), 41-44.

McCormick, K. \& Shofner, M. (2010). Here Comes Everybody: An Epistemic Approach to Teaching Ulysses in a Small College. Pedagogy, 10(2), 363-388.

McNall, S. (1975). Peer Teaching: A Description and Evaluation. Teaching Sociology, 2(2), 133-146.

Mendenhall M. \& Burr, W. (1983). Enlarging the Role of the Undergraduate Teaching Assistant. Teaching of Psychology, 10(3), 184-186.

Murray, J. (2015). Merging Teaching Practicum, Leadership Seminar, and Service Learning

Journal of the Scholarship of Teaching and Learning, Vol. 17, No. 3, July 2017.

josotl.indiana.edu 
Merging Teaching Practicum, Leadership Seminar, and Service Learning. Journal of the Scholarship of Teaching \& Learning, 15 (6), 63-77.

Socha, T. (1998). Developing an Undergraduate Teaching Assistant Program in Communication: Values, Curriculum, and Preliminary Assessment. Journal of the Association for Communication Administration, 27(2), 77-83.

Smith, T. (2008). Integrating Undergraduate Peer Mentors into Liberal Arts Courses: A Pilot Study. Innovative Higher Education, 33(1), 49-63.

Streitwieser, B., \& Light, G. (2005). Undergraduates Leading Undergraduates: Peer Facilitation in a Science Workshop Program. Innovative Higher Education, 30(4) 269-288.

Tompkins, J. (1990). Pedagogy of the Distressed. College English, 52(6), 653-660.

Topping, K., \& Ehly, S. (2001). Peer assisted learning: A framework for consultation. Journal of Educational and Psychological Consultation, 12, 113-132.

Trimble, R. \& Carter, C. (1980). Test anxiety workshops using undergraduates as leaders. Personnel and Guidance Journal, 59(3), 173-175.

Journal of the Scholarship of Teaching and Learning, Vol. 17, No. 3, July 2017. 